\title{
Multiscale Tail Risk Connectedness of Global Stock Markets: A LASSO-Based Network Topology Approach
}

\author{
Yuting Du $\mathbb{D}^{1},{ }^{1}$ Xu Zhang $\mathbb{D}^{1,2}$ Zhijing Ding $\mathbb{D}^{3},{ }^{3}$ and Xian Yang $\mathbb{D}^{1}$ \\ ${ }^{1}$ School of Management Science and Engineering, Nanjing University of Information Science \& Technology, \\ Nanjing 210044, China \\ ${ }^{2}$ Nanjing Digital Financial Industry Research Institute Co., Ltd., Nanjing 210018, China \\ ${ }^{3}$ Chang Wang School of Honors, Nanjing University of Information Science \& Technology, Nanjing 210044, China \\ Correspondence should be addressed to Xu Zhang; 002899@nuist.edu.cn
}

Received 2 October 2021; Revised 28 December 2021; Accepted 3 January 2022; Published 24 January 2022

Academic Editor: Giacomo Fiumara

Copyright (c) 2022 Yuting Du et al. This is an open access article distributed under the Creative Commons Attribution License, which permits unrestricted use, distribution, and reproduction in any medium, provided the original work is properly cited.

\begin{abstract}
Due to the advent of deglobalization and regional integration, this article aims to adopt LASSO-based network connectedness to estimate the multiscale tail risk spillover effects of global stock markets. The results show that tail risk varies across frequencies and shocks. In static analysis, the risk is centered mostly on the developed European and North American markets at a low frequency (long term), and regionalization is imposed on the moderate frequency (midterm). Moreover, emerging markets could be sources of risk spillover, especially at the highest frequency (short term) where there is no absolute risk center. In dynamic analysis, we use rolling window estimation and find that different frequencies identify distinct episodes of shocks, which provides us with the reason for the diverse risk centers at different time scales in static analysis. Our findings provide heterogeneous financial practitioners, regulators, and investors with diverse characteristics of stock markets under multiple time horizons and help them operate their own trading strategies.
\end{abstract}

\section{Introduction}

The "diabolic loop" between sovereign risk and banking risk during the European debt crisis implies that the downward performance of macro institutions goes hand in hand with the financial crisis. From a bird eye's perspective, one adverse shock emerging in one country may cause the crash of the global financial system. The prominent financial crisis in 2008 and even the global shock of the COVID-19 pandemic could trigger risk contagion in both sovereign countries and international dimensions, which has drawn widespread concern and study in the prevailing research on global risk connectedness [1-6].

In financial systems, extreme risk events tend to result in the abnormal flow of capital, thus causing the default of banking institutions. Then, the "tail risk" spreads across the departments or the entire financial system. These events are inevitably linked to economic policy uncertainty (EPU), which leads to fluctuating confidence among investors.
Recently, EPU has been documented to comove stock markets [7-10]. However, there is risk resonance both with one single market and across the entire financial system and ergo the acceleration of the risk contagion between the markets and the expansion of financial crises [11]. Therefore, the nonlinear approach of network connectedness was introduced. Capable of finding the exact or correlated risk centers, the network analysis embedded in the connectedness research possesses favorable properties for effective information concerning systemically important economic entities in the context of the overall system. A number of studies have applied parallel methods at the country, regional, or global level [5, 12-18]. For example, at the country level, Yang et al. [19] apply four indicators to identify tail risk events and measure the risk contribution of financial institutions and real estate companies in China's A-share market by combining network topology analysis and find that the contagion center has changed under different events. At the global level, Guo et al. [16] combine the time- 
varying financial network model and FARM-selection approach to analyze the tail risk contagion between international financial markets during COVID-19 and find that the key markets of networks are related to the epidemic countries. However, the degree distribution used in network analysis refers to the overall description of the degree of nodes in the network [16], that is, the number of directly connected edges, which fails to gauge the exact percentage of risk contribution among others. The same is true for the interconnectedness measures in the Granger causality networks by Wang et al. [20], and the motif-synchronizationbased network by Pereira et al. [21]. Moreover, though filtering the impacts from other markets as opposed to the Pearson correlation, the partial correlation coefficient applied by Ren et al. [22] and detrended cross-correlation analysis (DCCA) coefficient correlation by Pereira et al. [23] still would not provide the precise directional risk contributions from each other. For example, giving the partial correlation of the two markets $\mathrm{A}$ and $\mathrm{B}$, we cannot draw a conclusion of whether A or B influences the other more. Therefore, compared to the existing articles involving the network connectedness, the asymmetry method by Diebold and Yilmaz [3] outperforms the networks above, which is also applied by Mensi et al. [24], Liao et al. [25], Demirer et al. [26], Zhang and Ding [27], Yang et al. [28], Li [29], Abuzayed et al. [30], etc.

Due to the heterogeneity and complexity of the financial markets [31], and there may be opposite observations when it comes to the relationship between stock returns and macroeconomic variables like inflation [32], we seek to discover the global network connectedness among stock markets at multiple frequencies in this paper. Emmanuel et al. utilized the empirical mode decomposition (EMD) and found that stock prices on the GSE are affected by real economic growth but not short-lived market fluctuations [33]. But, the wavelet decomposition can solve the problem of poor orthogonality of each modal component value in EMD [34], so we choose the well-known wavelet method in financial time series data research $[9,32,35-40]$. The method has provided significant evidence in the field of stock market risk contagion in the frequency domain. For example, Marfatia [38] studied the comovement of risks at the country and regional levels. The conclusion is that the comovement of risks between the US market and European markets is strong mostly at lower frequencies and weaker at higher frequencies but more connected within regions. Zhou et al. [41] found that shocks caused by irregular events (the highfrequency component) can pose sudden and short-term risk contagion to stock returns while the shocks caused by extreme events (the low-frequency component) can pose positive and sustained risk contagion to stock returns. Zhang and Ding [27] discovered that when frequency is combined with regimes, the risk spillover center will undergo subversive changes in the long run. And BTC will be more robust at extreme values, while cryptocurrencies with smaller market capitalization will be stronger in the medium term.

Wavelet packet decomposition (WPD) uses the wavelet approach. Michis and Sapatinas [42] proposed a method that relies on wavelet packet transforms of the existing continuous explanatory variables to increase the efficiency of regression coefficient estimation. Despite the method being insufficiently utilized in finance, wavelet packet decomposition is a typical signal decomposition approach at both the approximate and detailed scales and outperforms traditional wavelet analysis. Despite the possibility of the occurrence of noise when further decomposing the detailed part of the signal, we could prevent this by selecting the appropriate number of the decomposition level. Hence, we apply the WPD to find out the variation of the network features under multiple frequencies and provide investors with more targeted advice.

There have been papers exploring spillover effect among global stock markets [22, 23, 29, 30]; however, stock markets in some emerging countries or developed countries are left out. Regarding measuring the network connectedness among numerous indicators, high-dimensional estimation has been solved by Demirer et al. [26] using the "least absolute shrinkage and selection operator" (LASSO). This document applied LASSO to shrink, select, and estimate the high-dimensional network between the world's top banks and found clear geographic clustering in bank equity. Besides, cross-country connectedness moves significantly during crises. In addition, some other studies have used this method for network estimation or risk contagion analysis $[43,44]$.

Our article contributes to the literature in three ways. First, we employ a wavelet packet to examine the multifrequency (multiscale) risk spillover connectedness among stock markets across the globe, that is, the characteristics of the risk contagion effect between different countries from the long term to the short term. Second, we solve the dimension problem in line with Demirer et al. [26] who compensated for the incomplete coverage of markets in previous researches. Third, we present powerful empirical observations. For example, the tail risk at a low frequency (long term) centers on developed countries, and there is regionalization in the risk contagion at a moderate frequency (midterm). Even emerging markets can be an unstable source of risk at the highest frequency (short term), which improves the effectiveness of combining macroprudential and monetary policy. Specifically, such an observation can be used by central banks. When there is turbulence in certain stock markets, regardless of whether the markets are located in developed or emerging countries, target policy (from the long term to the short term) and alert mechanisms could be established according to the nature and duration of the episodic shocks, thus helping stabilize the confidence of investors and promote the benign operation of the capital markets. Moreover, portfolio risk managers, international investors, and speculators may uncover the complex phenomenon in global stock markets and make better trading strategies according to their own trading time horizons. Overall, this article broadens our horizons (numerous markets in both developed and emerging countries are included) and captures frequency properties in a more profound way (the use of WPT) when observing the channel of stock market risk contagion. 
The remainder of the article is structured as follows. Section 2 outlines the econometric method. Section 3 presents the data description. Section 4 provides the empirical results, and Section 5 concludes the paper.

\section{Methodology}

2.1. Wavelet Packet Decomposition. The traditional wavelet transformation, which is limited to decomposing the approximation portion, discretizes the scale and translation parameters. The wavelet packet transformation optimizes the method by further splitting the detailed part of the signal. It divides the frequency band into several levels, flexibly selecting the best combination of the resultant wavelet constituents; and the corresponding signal spectrum improves the time frequency analysis ability. For the sake of extracting more accurate information on stock returns, we employ wavelet packet decomposition (WPD) to further decompose the high-frequency subset of daily trading data.

Wavelet packets generalize the link between multiresolution approximations and wavelets. A space $V_{j}$ of a multiresolution approximation is decomposed in a lowerresolution space $V_{j+1}$ plus a detail space $W_{j+1}$. This is done by dividing the orthogonal basis $\left\{\phi_{j}\left(t-2^{j} n\right)\right\}_{n \in Z}$ of $V_{j}$ into two new orthogonal bases: $\left\{\phi_{j+1}\left(t-2^{j+1} n\right)\right\}_{n \in Z}$ of $V_{j+1}$ and $\left\{\psi_{j+1}\left(t-2^{j+1} n\right)\right\}_{n \in Z}$ of $W_{j+1}$. The decompositions of $\phi_{j+1}$ and $\psi_{j+1}$ in the basis $\left\{\phi_{j}\left(t-2^{j} n\right)\right\}_{n \in Z}$ are specified by a dual low-pass filter $h[n]$ and a dual high-pass filter $g[n]$. In accordance with Mallat [45], we define $g[n]=(-1)^{1-n} h[1-n]$. Regarding the wavelet packet decomposition,

$$
\begin{aligned}
d_{j+1}^{2 p}[k] & =\sum_{n=-\infty}^{+\infty} h[n-2 k] d_{j}^{p}[n], \\
d_{j+1}^{2 p+1}[k] & =\sum_{n=-\infty}^{+\infty} g[n-2 k] d_{j}^{p}[n],
\end{aligned}
$$

where $0<p \leq 2^{j}-1$ and $d_{j+1}^{2 p}[k]$ and $d_{j+1}^{2 p+1}[k]$ are the coefficients of the wavelet packet subgeneration.

Figure 1 presents a wavelet packet decomposition tree formed by three-level wavelet packet decomposition.

In a frequency-ordered wavelet packet tree, the original signal $S$ is decomposed into successive approximation parts $(A)$ of the signal and detailed parts $(D)$.

2.2. Spillover Network Connectedness. Following Diebold and Yilmaz [3, 46], the measurement of connectedness is based on the shares of the forecast error variation from each stock market, which can be realized using generalized variance decomposition (GVD) [3] under the vector autoregression (VAR) framework.

To present the spillover connectedness table, first, we define the $\mathrm{H}$-step generalized variance decomposition matrix $\theta_{i j}^{g}(H)$ of element $j$ to $i$ :

$$
d_{i j}^{g H}=\frac{\sigma_{j j}^{-1} \sum_{h=0}^{H-1}\left(e_{i}^{\prime} \Theta_{h} \Sigma e_{j}\right)^{2}}{\sum_{h=0}^{H-1}\left(e_{i}^{\prime} \Theta_{h} \Sigma \Theta_{h}^{\prime} e_{i}\right)},
$$

where $e_{j}$ is a selection vector with the $j$ th element unity and zeros elsewhere, $\Theta_{h}$ is the coefficient matrix of the moving average VAR, $\Sigma$ is the covariance matrix of the shock vector in the VAR, and $\sigma_{j j}$ is the $j$ th diagonal element of $\Sigma$.

Hence, we define the pairwise directional connectedness from market $j$ to $i$ as

$$
C_{i \leftarrow j}^{H}=d_{i j}^{H} .
$$

The net contagion can be defined as

$$
N C_{i \leftarrow j}^{H}=C_{i \leftarrow j}^{H}-C_{j \leftarrow i}^{H} .
$$

The label "From" in the connectedness table is the total directional connectedness from other markets to market $i$ :

$$
C_{i \leftarrow .}^{H}=\sum_{j=1, j \neq i}^{N} d_{i j}^{H} .
$$

The label "To" in the connectedness table is the total directional connectedness to other markets from market $j$ :

$$
C_{. \leftarrow j}^{H}=\sum_{i=1, i \neq j}^{N} d_{i j}^{H} .
$$

Then, the net contagion from market $i$ to all the other markets is

$$
N C_{i}^{H}=C_{. \leftarrow i}^{H}-C_{i \leftarrow .}^{H} .
$$

Finally, the total stock market connectedness can be defined as

$$
C^{H}=\frac{1}{n} \sum_{\substack{i, j=1 \\ i \neq j}}^{n} d_{i j}^{H} .
$$

Based on the denotations above, the stock market connectedness is shown as follows (Table 1).

2.3. Application of the LASSO in High-Dimensional Estimation. The prevailing LASSO blending shrinkage and selection can be applied to estimate the high-dimensional VAR model. The sparsity in the implied network connectedness is not necessarily imposed, so we focus our work on the effects of shrinkage and selection on the approximating VAR [26]. The ordinary least square (OLS) has its drawbacks like low prediction accuracy and large variance and can be improved by subset selection and ridge regression, however which is extremely variable or does not give an easily interpretable model. As introduced by Tibshirani [47], the basic idea of the LASSO is to introduce a penalty factor on the basis of the OLS estimation to constrain the estimator, thus making the final model interpretable and stable.

The LASSO estimate $\widehat{\beta}$ is defined by

$$
\widehat{\beta}=\arg \min \left\{\sum_{i=1}^{N}\left(y_{i}-\sum_{j} \beta_{j} x_{i j}\right)^{2}\right\},
$$




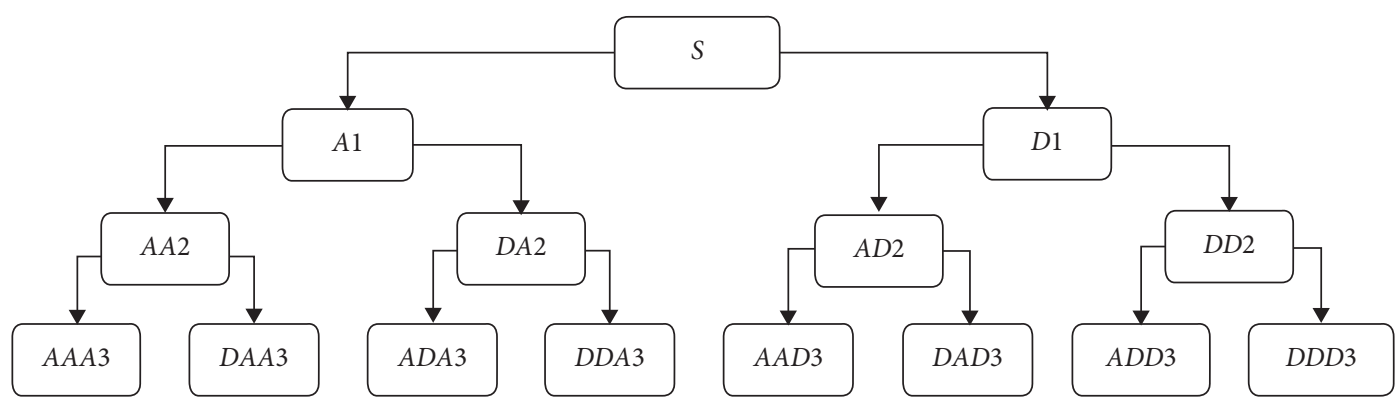

Figure 1: Three-level wavelet packet decomposition tree.

TABLE 1: Stock market connectedness table.

\begin{tabular}{lccccc}
\hline & $x_{1}$ & $x_{2}$ & $\ldots$ & $x_{n}$ & From \\
\hline$x_{1}$ & $d_{11}^{H}$ & $d_{12}^{H}$ & $\ldots$ & $d_{1 n}^{H}$ & $C_{i \leftarrow 1}^{H}$ \\
$x_{2}$ & $d_{21}^{H}$ & $d_{22}^{H}$ & $\ldots$ & $d_{2 n}^{H}$ & $C_{i \leftarrow 2}^{H}$ \\
$\ldots$ & $\ldots$ & $\ldots$ & $\ldots$ & $\ldots$ \\
$x_{n}$ & $\ldots$ & $\ldots$ & $d_{n n}^{H}$ & $C_{i \leftarrow n}^{H}$ \\
\hline To & $d_{n 1}^{H}$ & $d_{n 2}^{H}$ & $\ldots$ & $C_{. \leftarrow n}^{H}$ & $C^{H}$ \\
\hline
\end{tabular}

subject to

$$
\sum_{j}\left|\beta_{j}\right|^{q} \leq t
$$

where $X^{i}=\left(x_{i 1}, \ldots, x_{i p}\right)^{T}$ is the predictor variables, $y_{i}$ is the responses, the tuning parameter $t \geq 0$, and $q$ is minimized for smooth convex penalties that emerge in the penalized estimation.

$$
\widehat{\beta}=\arg \min \left[\sum_{i=1}^{N}\left(y_{i}-\sum_{j} \beta_{i} x_{i j}\right)^{2}+\lambda \sum_{j}\left|\beta_{j}\right|^{q}\right] .
$$

Along with the concave penalty functions nondifferentiable at the origin, the LASSO thus enjoys the preferred features of both subset selection and the ridge regression.

In accordance with Demirer et al. [26], we apply the adaptive elastic net, and the penalized estimation can be modified as

$\widehat{\beta}=\arg \min \left[\sum_{i=1}^{N}\left(y_{i}-\sum_{j} \beta_{i} x_{i j}\right)^{2}+\lambda \sum_{j} w_{j}\left(\frac{1}{2}\left|\beta_{i}\right|+\frac{1}{2} \beta_{i}^{2}\right)\right]$,

where $w_{i}=1 /\left|\widehat{\beta}_{i, O L S}\right|$ and $\lambda$ is the equation selected by 10 fold cross-validation.

\section{Data}

Irreversible globalization triggers financial risk spillover among sovereign economic entities. However, the complexity of a country's financial systems is such that it is difficult to determine which institutions or industries in which countries centralize the risk contagion. Fortunately, the representative stock indexes (e.g., S\&P 500) in a certain country are available. The market signals encompassed in stocks returns are essential to the assessment of the entire financial system. Additionally, some industry-avoided indexes such as the "S\&P TSX Canadian Midcap Index" concerning minor corporations are also included. Though markets with the same tail risk may cause different risk spillovers to others, that is, markets that are individually equally risky are not equally risky to other markets or systems [48] (e.g., an individually systemically important market that is so interconnected and large that it may cause more negative risk spillover effects to others than relatively small markets), the combined small entities can form a type of "large market" and may cause a sequence of risk contagion within the market or even put the overall financial system in danger, which should not be neglected.

In this paper, we select 85 stock indexes involving 61 countries and collect 3405 items of daily trading data from June 1, 2006, to March 5, 2021. Then, we calculate the logarithmic returns of the indexes. However, there exists a problem in which the index data are from different time zones. Inspired by Yang et al. [19], we use the two-day rolling average method for interpolation. The specific data are obtained from https://www.investing.com/.

We choose high-frequency daily return data to ensure the empirical accuracy of the rolling estimation. The wavelet packet decomposition for high-frequency signals adaptively solves our filtering problem by extracting precise subsignals through the return data.

The 61 countries we selected were located on five continents. Among the 85 indexes, 18, 7, 26, 31, and 3 indexes are from America, Africa, Asia, Europe, and Oceania, respectively. The specific indexes by continent are listed in Table 2. The abbreviations of the indexes are set as "index abbreviation. Country abbreviation." For example, "MERV.AR" is the "S\&P Merval of Argentina."

\section{Empirical Results}

4.1. Multiscale Tail Risk. In this paper, we employ the most common measure of risk by financial institutions-the 
TABLE 2: Stock indexes in different countries.

\begin{tabular}{|c|c|c|c|}
\hline Continent & Country & Index & Abbreviation \\
\hline \multirow{18}{*}{ America } & \multirow{2}{*}{ Argentina } & S\&P Merval & MERV.AR \\
\hline & & S\&P/BYMA Argentina general & IBG.AR \\
\hline & \multirow{4}{*}{ Brazil } & BOVESPA & BVSP.BR \\
\hline & & Midlarge cap index & MLCX.BR \\
\hline & & Small-cap index & SMLL.BR \\
\hline & & S\&P/TSX composite & GSPTSE.CA \\
\hline & \multirow[t]{2}{*}{ Canada } & S\&P/TSX Canadian midcap & SPTSEM.CA \\
\hline & & S\&P/TSX Canadian small cap & SPTSES.CA \\
\hline & Chile & S\&P CLX IPSA & SPIPSA.CL \\
\hline & Colombia & FTSE Colombia & FTWICOLL.CO \\
\hline & Costa Rica & Costa Rica indice accionario & IACR.CR \\
\hline & Mexico & S\&P/BMV IPC & MXX.MX \\
\hline & \multirow[t]{3}{*}{ Peru } & FTSE Peru & FTWIPERL.PE \\
\hline & & NASDAQ composite & NASDAQ.US \\
\hline & & S\&P500 & SPX.US \\
\hline & \multirow[t]{3}{*}{ USA } & Dow jones industrial average & DJI.US \\
\hline & & Nasdaq 100 & NDX.US \\
\hline & & US small cap 2000 & RUT.US \\
\hline \multirow{7}{*}{ Africa } & \multirow{2}{*}{ Botswana } & BSE domestic company & DCIBT.BW \\
\hline & & BSE foreign company & FCIBT.BW \\
\hline & Egypt & EGX30 & EGX30.EG \\
\hline & Kenya & Kenya NSE 20 & NSE20.KE \\
\hline & Morocco & Moroccan all shares & MASI.MA \\
\hline & Tunisia & Tunindex & TUNINDEX.TN \\
\hline & South Africa & South Africa top 40 & JTOPI.ZA \\
\hline \multirow{26}{*}{ Asia } & \multirow{2}{*}{ Hong Kong } & Heng Sheng & HS.HK.CN \\
\hline & & Hang Seng China affiliated corps (CCI) & HSCC.HK.CN \\
\hline & \multirow{2}{*}{ Mainland China } & Shanghai composite & SSEC.CN \\
\hline & & SZSE component & SZI.CN \\
\hline & \multirow{3}{*}{ Indonesia } & Jakarta stock exchange composite index & JKSE.ID \\
\hline & & Jakarta stock exchange LQ45 & JKLQ45.ID \\
\hline & & NIFTY small cap 100 & NIFSMCP100.ID \\
\hline & Israel & TA35 & TA35.IL \\
\hline & India & Nifty 50 & NSEI.IN \\
\hline & Jordan & Amman SE general & AMGNRLX.JO \\
\hline & \multirow{2}{*}{ Japan } & Nikkei 225 & N225.JP \\
\hline & & TOPIX & TOPIX.JP \\
\hline & Korea & KOSPI & KS11.KR \\
\hline & Lebanon & BLOM stock & BLSI.LB \\
\hline & Sri Lanka & CSE all share & CSE.LK \\
\hline & Mauritius & Semdex & MDEX.MU \\
\hline & Malaysia & FTSE Malaysia & FTWIMALL.MY \\
\hline & Oman & MSM 30 & MSI.OM \\
\hline & Philippines & FTSE Philippines & FTWIPHLL.PH \\
\hline & Pakistan & Karachi 100 & KSE.PK \\
\hline & Qatar & QE general & QSI.QA \\
\hline & Saudi Arabia & Tadawul all share & TASI.SA \\
\hline & Singapore & FTSE Singapore & FTWISGPL.SG \\
\hline & Thailand & SET index & SETI.TH \\
\hline & Turkey & BIST 100 & XU100.TR \\
\hline & Vietnam & $\mathrm{VN}$ & VNI.VN \\
\hline
\end{tabular}


TABLE 2: Continued.

\begin{tabular}{|c|c|c|c|}
\hline Continent & Country & Index & Abbreviation \\
\hline \multirow{31}{*}{ Europe } & Austria & FTSE Austria & FTWIAUTE.AT \\
\hline & \multirow{3}{*}{ Belgium } & BEL 20 & BFX.BE \\
\hline & & BEL mid & BELM.BE \\
\hline & & BEL small & BELS.BE \\
\hline & Switzerland & SWI 20 & SSMI.CH \\
\hline & Czech Republic & FTSE Czech Republic & FTWICZHL.CZ \\
\hline & Denmark & OMX Copenhagen all shares & OMXCGI.DK \\
\hline & Spain & IBEX35 & IBEX35.ES \\
\hline & \multirow{3}{*}{ Finland } & OMX Helsinki 25 & OMXH25.FI \\
\hline & & OMX Helsinki midcap & OMXHMCPI.FI \\
\hline & & OMX Helsinki small-cap PI & OMXHSCPI.FI \\
\hline & \multirow{2}{*}{ France } & CAC 40 & FCHI.FR \\
\hline & & CAC mid \& small & CACMS.FR \\
\hline & UK & FTSE100 & FTSE.GB \\
\hline & \multirow{2}{*}{ Germany } & DAX & DAX.GE \\
\hline & & DAX midcap & MDAXI.GE \\
\hline & Greece & FTSE/ATHEX large cap & ATF.GR \\
\hline & Croatia & CROBEX & CRBEX.HR \\
\hline & Hungary & FTSE Hungary & FTWIHUNL.HU \\
\hline & Ireland & FTSE Ireland & FTWIIRLE.IE \\
\hline & Iceland & ICEX main & OMXIPI.IS \\
\hline & Italy & FTSE MIB & FTMIB.IT \\
\hline & Netherlands & AEX & AEX.NL \\
\hline & Norway & Oslo OBX & OBX.NO \\
\hline & Poland & WIG20 & WIG20.PL \\
\hline & Portugal & PSI all share gross return & BVLG.PT \\
\hline & \multirow{2}{*}{ Russia } & MOEX Russia & IMOEX.RU \\
\hline & & RTSI & IRTS.RU \\
\hline & Sweden & OMX Stockholm 30 & OMXS30.SE \\
\hline & Slovenia & Blue-Chip SBITOP & SBITOP.SI \\
\hline & Ukraine & PFTS & PFTSI.UA \\
\hline \multirow{3}{*}{ Oceania } & \multirow{2}{*}{ Australia } & S\&P/ASX 200 & AXJO.AU \\
\hline & & S\&P/ASX midcap 50 & AXMD.AU \\
\hline & New Zealand & NZX 50 & NZ50.NZ \\
\hline
\end{tabular}

value-at-risk (VaR) - focusing on the risk of an individual institution. We use the quantile $\mathrm{VaR}(q-\mathrm{VaR})$, which is the maximum dollar loss of a market within a $q$-confidence interval.

To calculate the multiscale tail risk, we first calculate the index returns at different scales. We utilize Shannon wavelet packets [45] for decomposition, which are computed using perfect discrete low-pass and high-pass filters. When the decomposition level triples, the decomposed returns formed are presented in Figure 2, where we show the S\&P 500 as an example. For notation, we label each scale frequency from low to high as Dn $(n=1,2, \ldots, 8)$. Inspired by Huang [36], we set the coarse scales of the subreturns as D1 and D2, that is, the long-term scales; the fine scales as D3, D4, D5, and D6, that is, the midterm scales; and the exquisite scales as D7 and D8, that is, the short-term scales. From an abstract perspective, the S\&P 500 return data presented in frequency order intuitively vary greatly not only in the density of fluctuations but also in the range of the returns. That is, in detail, from approximate to detailed scales, the density of the fluctuations is commonly higher at the fine and exquisite scales than that at the coarse scales. Moreover, the S\&P 500 returns during the 2008 financial crisis period and the 2020
COVID-19 outbreak experienced extreme levels at all frequencies. Besides, behind only to those two events, a high density of fluctuations occurred when the US's sovereign credit rating was downgraded by one notch on August 5, 2011. Additionally, with the range of the most approximate scale from -0.03 to less than 0.02 and the range of the most detailed scale from -0.05 to more than 0.05 , the distinctions indicate that the stock markets concentrate their fluctuations on short-term signals; therefore, extracting information from the short-term scales may help discover the inherent characteristics of stock market risk movements.

Having viewed the stock index returns at different scales, we now turn to the tail risk measured by the VaR. Figure 3 presents the VaRs of the stock market indexes. Despite the fact that the VaRs at the exquisite scales fluctuate with smaller ranges than those at the approximate scales, the dynamic evolution of the VaRs at all scales reacts dramatically to major risk events, with the 2008 Lehman Brothers bankruptcy and the 2020 COVID-19 outbreak events standing out. As for the 2008 financial crisis, the stock markets of the US and main European countries sharply fluctuated, and the tail risk reached almost 0.06 while the main Asian countries contributed less than 0.04. The 

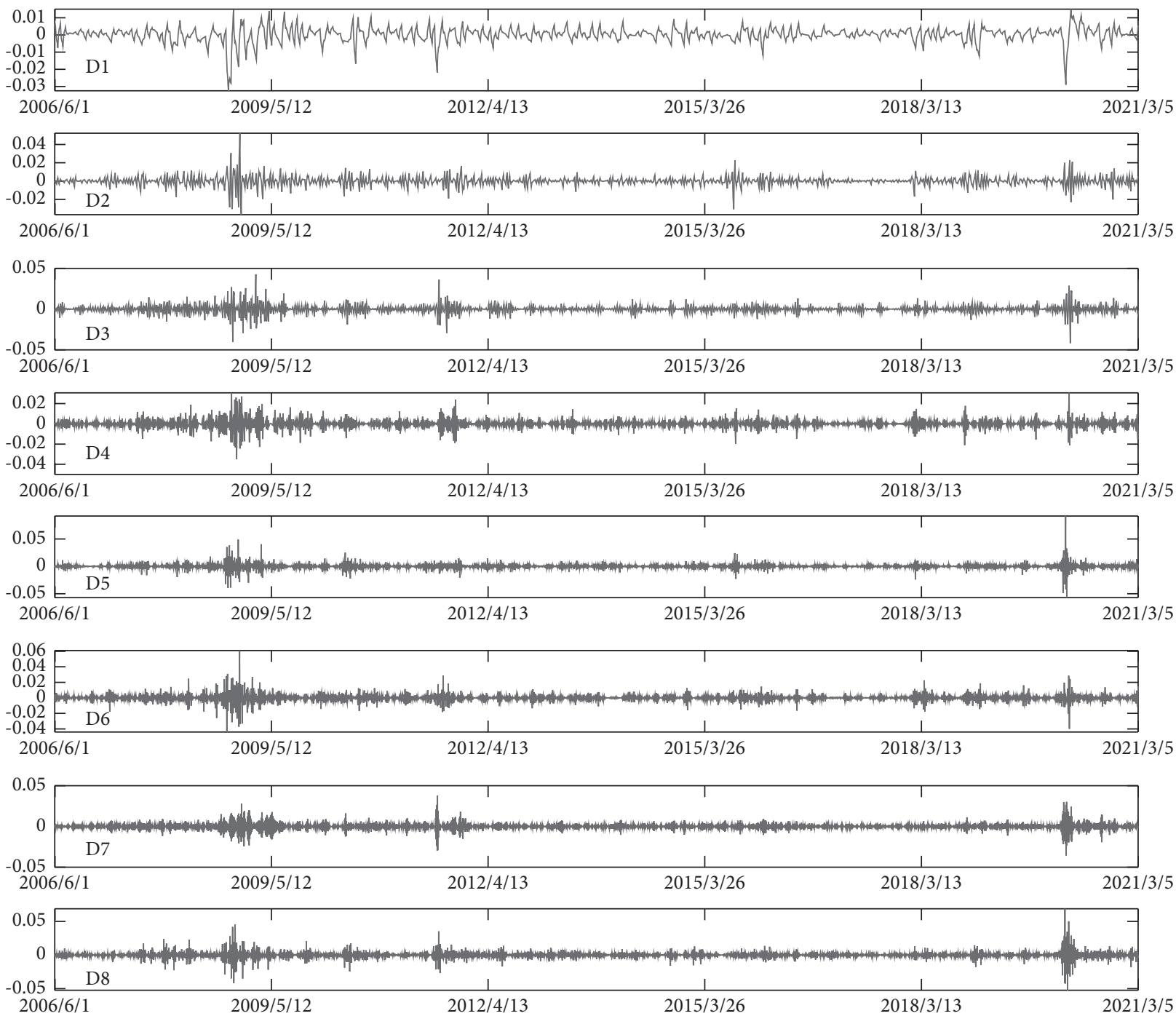

FIgURE 2: The subseries of WPD in time domain (SPX.US index return).

subsequent EU credit crisis-related events (Event 2 \& Event 6) lead the VaRs of each stock market to periodic peaks. We also discover that the fluctuation of stock markets triggers direct risk growth; simultaneously, investors are vulnerable to adverse economic shocks such as the sovereign credit downgrade of the world's largest economy and economic policy uncertainty concerning Brexit or monetary policy, and these events cause indirect risk absorption. Finally, even natural disasters such as tsunamis and major public emergencies can trigger extreme volatility in stock markets.

4.2. Multiscale Risk Spillover Effect. In this section, we research both the static (full sample) and dynamic (rolling sample) risk connectedness between markets.

4.2.1. Static Analysis. Using the stock market risk spillover connectedness table, first, we examine the tail risk spillover of global stock markets for the full sample. In this paper, we focus on the top $10 \%$ of the off-diagonal pairwise connectedness values, which account for most of the risk spillover from or to other stock markets. At all frequencies, the total connectedness index is $77.92 \sim 95.09 \%$, and the average market risk spillover is more than $85 \%$, which means that stock market risks are mostly from external stock markets.

Regarding the total "From" and "To" distribution, at a low frequency (scale D1), apparently, some blocks of high pairwise directional connectedness (apart from the diagonal elements accounting for the risk within indexes) appear obviously in the columns of the US and European indexes. In addition, most of the risk can be attributed to shocks in Netherlands, the US, France, UK, Germany, Belgium, and Sweden, with the highest transmitter of Netherlands contributing $157.01 \%$ (as the number of European stock index nodes is much higher than the numbers of other continents, there is an inevitable problem that the variance decomposition results would be biased towards the European clustering with the risk of Netherlands being the highest) and the second highest of the US contributing 151.75\%. Though with a relatively high total "From" value $\left(C_{i \leftarrow .}^{H}\right)$ of $90.09 \sim 94.43 \%$, these stock markets remain the top most "Net" risk 

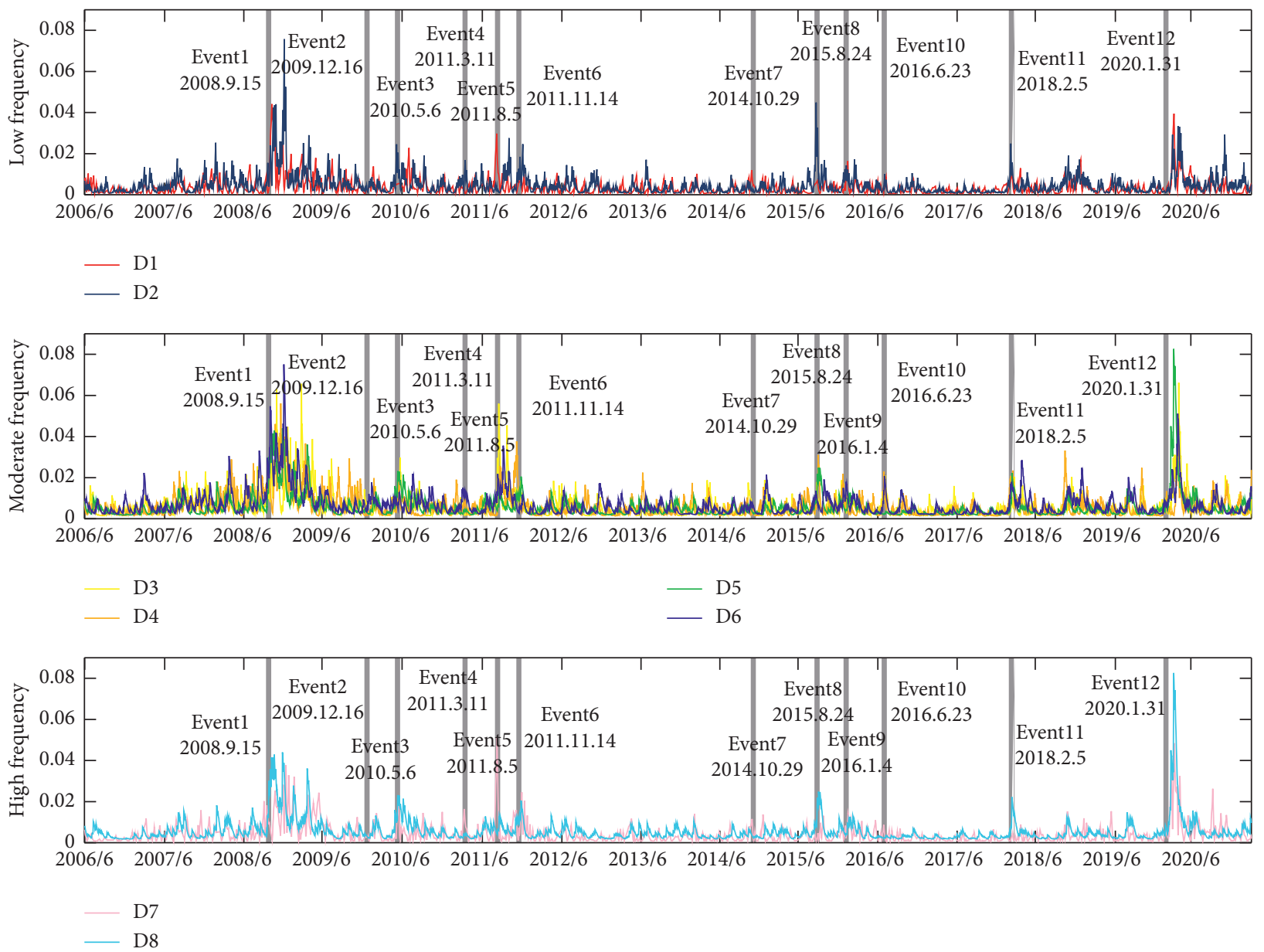

Figure 3: VaRs of SPX.US at multiple frequencies. Notes: (1) the 5\% VaR calculated under the confidence level of $95 \%$ is shown. (2) The shaded areas mark the major risk events between June, 2006, and March, 2021. The marked events are listed as follows: Event 1: Lehman bankruptcy (September15, 2008); Event 2: S\&P downgraded Greece's long-term sovereign credit rating from A- to BBB+ (December 16, 2009); Event 3: the US stock market flash crash (May 6, 2010); Event 4: Japan was hit by a 9.0 magnitude earthquake, followed by a tsunami (March 11, 2011); Event 5: the United States lost its AAA long-term sovereign credit rating and lowered it by one notch to AA+ (August 5, 2011); Event 6: APEC leaders issued a statement that the global economy is facing significant downside risks, partly affected by the European debt crisis (November 14, 2011); Event 7: quantitative easing has officially ended in the US (October 29, 2014); Event 8: major stock market disaster (August 24, 2015); Event 9: the first trading day after the "circuit breaker" mechanism was introduced (January 4, 2016); Event 10: UK voted in a referendum to exit from the European Union (June 23, 2016); Event 11: US stocks tumbled, with the Dow recording its biggest intraday point drop ever, and currencies tumbled (February 5, 2018); Event 12: WHO has classified the COVID-19 outbreak as a "public health emergency of international concern" (January 31, 2020). (3) VaRs of other indexes are available.

transmitters, with net contribution rates of 40.06 63.68\%. At scale D2, the average risk spillover "To" others $\left(C_{\leftarrow \leftarrow j}^{H}\right)$ is higher than that at scale D1. The most evident change is that China reverses to be the net transmitter compared to scale D1, and its total risk to others rises to $189.74 \%$; however, the total risk from others stays in the range of 76 86\%.

At a moderate frequency (scales D3 D6), the average connectedness from or to others $\left(C^{H}\right)(89.15 \%)$ is higher than those at the approximate and exquisite scales $(80.34 \sim 81.61 \%)$. This indicates that, in the moderate frequency or, namely, in the medium run, the stock markets are more connected and more likely to receive risks from external markets or shocks. In addition, markets show instability when playing the role as net risk transmitters $\left(N C_{i \leftarrow j}^{H}>0\right)$ or net risk receivers $\left(N C_{i \leftarrow j}^{H}<0\right)$. For example, the Nasdaq 100 switches to a net risk transmitter at scale D6, and the NIFTY small caps 100 becomes a net risk transmitter at scales D3 and D4. Besides, though switching between net transmitters and net receivers, the net contributions of some indexes only experience a slight change. For example, the FTWIIRLE.IE's (Ireland's) net risk spillover to other markets ranges within -3.59 6.09\%. Most European countries' roles as net transmitters have not changed.

At a high frequency (scales D7 D8), US markets switch from net risk transmitters to net risk receivers, with average net contributions decreasing by $32.47 \%$ at scale D8. Surprisingly, only $28.24 \%$ of the markets are net risk transmitters. Among them, the NSE20.KE (Kenya) becomes the top risk transmitter, and Morocco is the second. However, the markets in Brazil, China, Japan, Vietnam, Australia, and New Zealand are all high-risk transmitters at scale D8. 
More specifically, we move on to the "From" distribution to find the directional risk transmitters to each country. At the most approximate scale D1, the risk spillover to others centers on North American and European countries. Among them, the SSMI.CH (Switzerland) becomes the largest risk receiver of the US stock markets, and the explanatory weight is $2.14 \sim 3.92 \%$. Other European countries such as UK, Germany, Sweden, France, Netherlands, and Finland (average percentage from the US in descending order) are also high-risk receivers of the US stock markets, and the explanatory weights are $1.80 \sim 2.95 \%$. Besides, the volatility of stock returns in Australia, South Africa, Israel, Malaysia, Japan, and Singapore from other continents can also be attributed to the US. The tightly correlated European countries show the highest connectedness value, with the main countries spreading risk to each other, and the highest percentage reaches $4.06 \sim 4.54 \%$. Though relatively geographically distant from Europe, the stock markets in Canada and the US are closely related to those in Europe; however, the variance contribution rate of the European stock markets reaches $1.59 \sim 2.93 \%$, which is less than what Canada and the US contribute to Europe.

At scale D2, the connectedness value of China increased to the top. Asian countries' market risks, such as those of Indonesia and Thailand, from mainland China were approximately $9.86 \%$ and $5.73 \%$, respectively. Another Asian country such as Sri Lanka receives as high as 8.23 percent risk from China. The Central American country Costa Rica and the South American country Brazil (small caps are excluded from the high receivers as the explanatory weights from SSEC and SZI are only 0.20 0.46 percent) may also receive risk from mainland China, with explanatory weights of $4.23 \%$ and $2.40 \%$, respectively. The DJIA and Nasdaq 100 show high correlations with the mainland China stock markets, with explanatory weights ranging from $2.18 \%$ to 3.68\%. Small caps in Finland, midcaps in Germany, and main caps in Iceland are subject to approximately $4.74-9.79 \%$ of the risk of mainland China.

At fine scales D3 D6, the transcontinental risk contagion effect is weakened, and the intracontinental effect is enhanced compared to the low-frequency scales. For example, at scale D3, the transcontinental effect of US risk contagion mainly occurs in a North African country (Tunisia $1.6 \%$ ), an Asian country (India 1.86\%), and European countries (Czech Republic 1.62\% and UK 1.63\%). Additionally, mainland China transmits market risk both within continents (Indonesia 1.92\%, Japan 3.97\%, and Korea $4.34 \%$ ) and across continents (Belgium 1.89\%, Czech Republic 3.6\%, and Finland 2.2\%) but is still inconspicuous. At scales D4 and D6, the risk contagion effect among all markets is similar, and there is a large gap between the largest risk transmitter and receiver, which is quite different from scales D3 and D5. For instance, at scale D6, the risk spillover from the Philippines reaches 35.18\% (Czech Republic), 21.97\% (Portugal), 12.90\% (Norway), 12.03\% (Italy), $8.39 \%$ (Finland), and 5.97\% (the US). However, at scale D5, the largest contribution is only $2.59 \%$.

At the exquisite scales D7 D8, the Hong Kong stock market becomes a relatively high-risk transmitter in Asia at scale D7, with the largest receiver Singapore (4.13\%). However, the Japanese market has significant impacts on the volatile returns of the Australian market (1.91\%). However, at scale D8, risk contagion contributions mainly come from African, Asian, South American, and Oceanic markets; and this result is different from that at the most approximate scale D1. Nevertheless, the results of the literature $[4,19,38,49]$ concerning forecasting future return fluctuations focus on the main developed countries, which agree with our results at the most approximate scale, in other words, the long-run characteristics. The results at the exquisite scales vary so much from each other that we ascribe this to the economic uncertainty of each country in the short run. That is, any shock or emergency occurring in one region may result in drastic volatility in one index in any region. Therefore, we should not concentrate so much on the shortterm characteristics of risk contagion found at the exquisite scales but pay close attention to the fine scales indicating the medium-term risk contagion within the correlated regions and the approximate scales capturing the long-term market risk movements across the globe.

(1) Ranking of Multiscale Net Risk Spillover Effect. Table 3 presents the ranking of the "Net" risk spillover effect at multiple scales. In this section, we focus on the ranking of global markets. The ranking rule of the low frequencies (scales D1 and D2) is that the top 15 net risk transmitters are mostly developed countries in Europe and America. Additionally, mainland China shifted from the low-risk ranking area at D1 to the high-risk ranking area at D2. Within America, the US ranks first at seven scales, followed by Canada and Brazil.

At the moderate frequency (scales D3 D6), low- or modest-risk members at the previous scales increase to be high-risk members, such as Indonesia, Kenya, Argentina, Japan, and the Philippines. The ranking of the US shows instability (SPX.US ranks 10 at D3, 5 at D6, 22 at D4, and 18 at D5), and part of the US market (the tech-heavy NDX.US) and Belgium market (BELS.BE with small caps) can even switch to a low-risk area at D3.

At a high frequency (D7 D8), the rankings are distinct from each other, with some African and Asian countries Kenya (1), Morocco (2), Vietnam (6), and Egypt (14) increasing to high-risk areas.

Although the ever-changing ranking results seem complicated, countries remaining in high- or low-risk areas at most frequencies (no less than 5 scales) can be obtained. The high-risk countries are listed as follows: Netherlands, the US, France, UK, Germany, Belgium, Sweden, and Finland. The low-risk countries are listed as follows: Ukraine, Botswana, Peru, Costa Rica, Jordan, Oman, Lebanon, Sri Lanka, Vietnam, Mauritius, Pakistan, and Qatar.

(2) Visualization of Risk Spillover Network Connectedness. Furthermore, we visualize the network connectedness (the diverse frequencies at different scales are naturally the "robustness check," which indicate the long- to short-term risk connectedness and connectedness results measured at different horizons $(H=6,12,18)$ are also available) in Figure 4. 


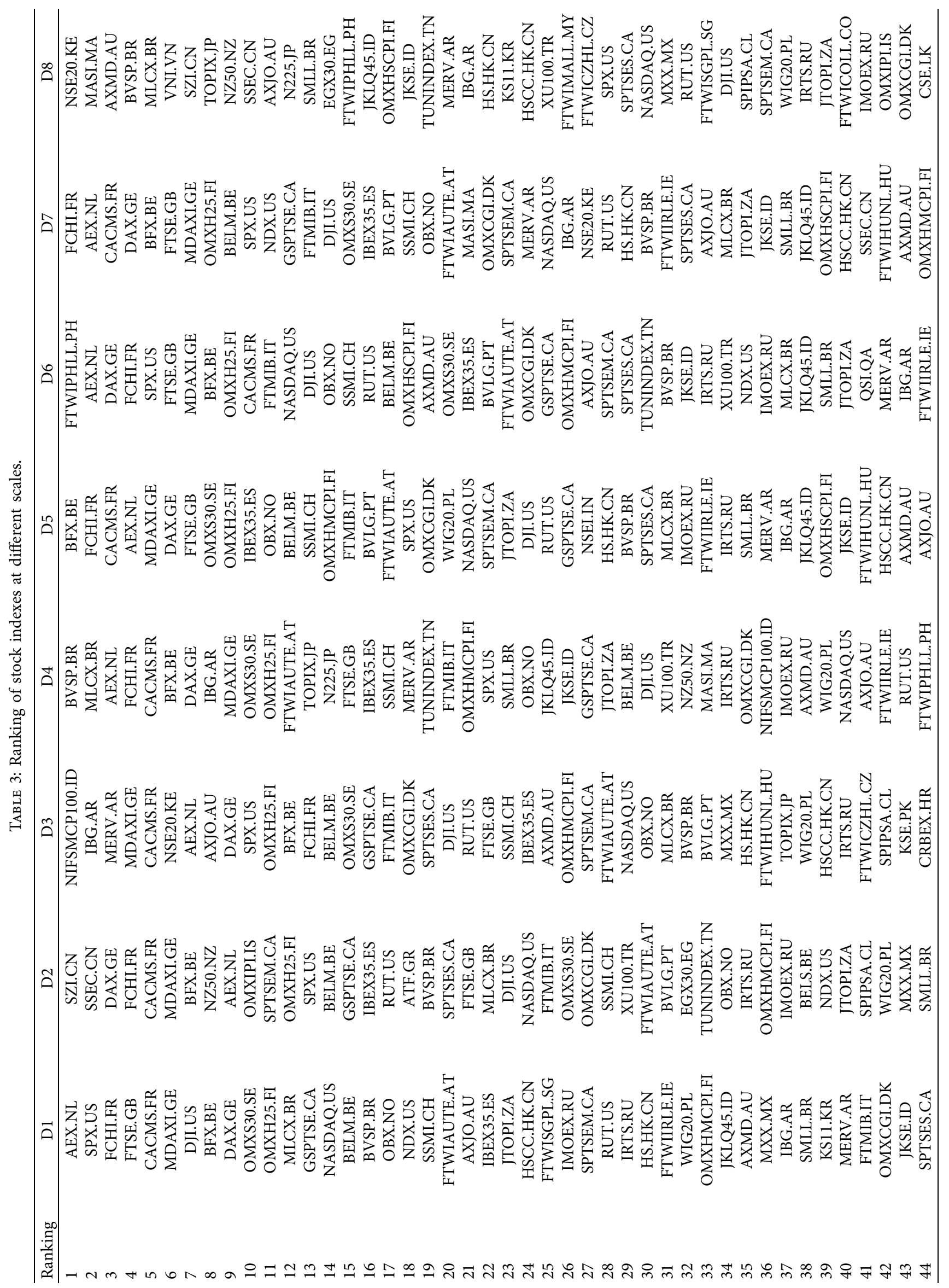




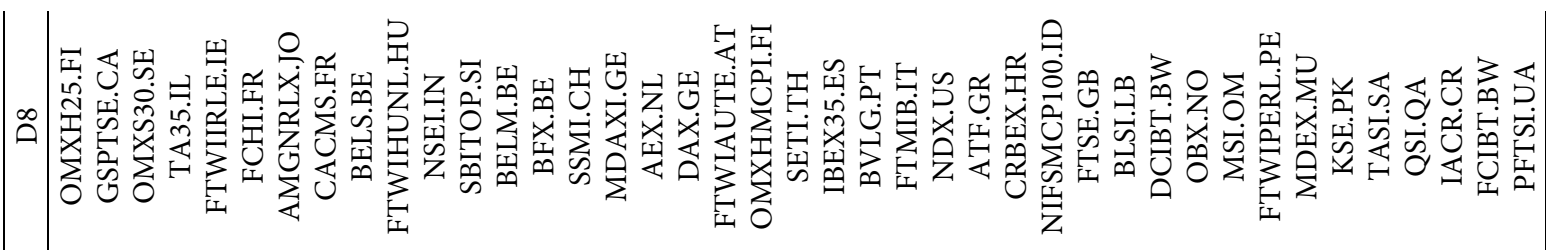

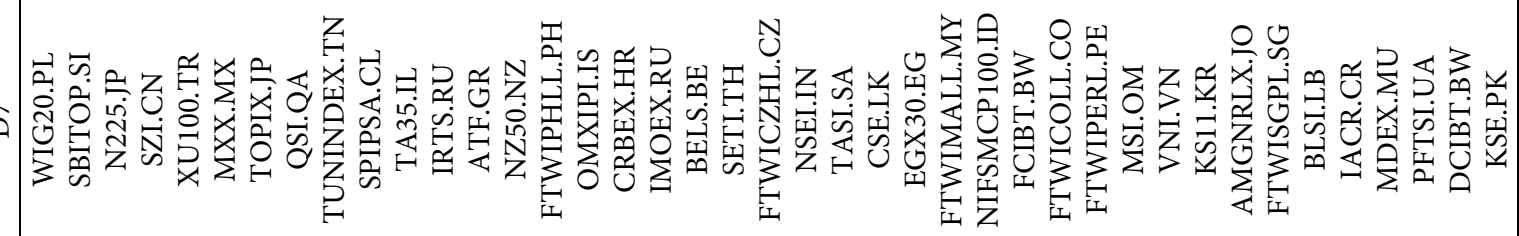

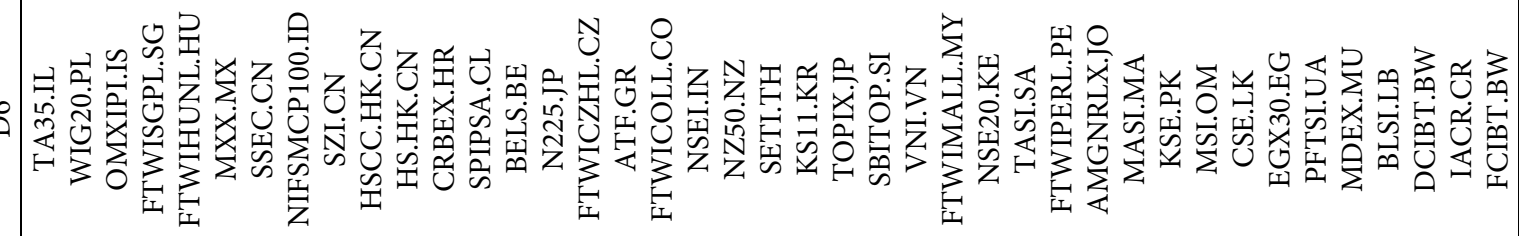

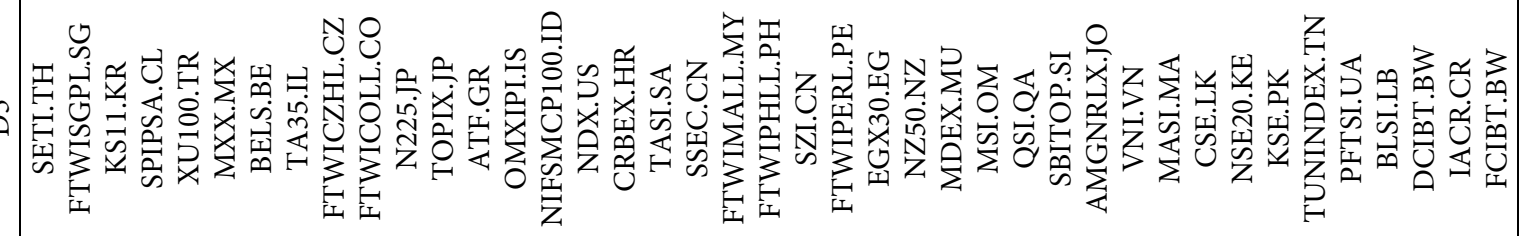

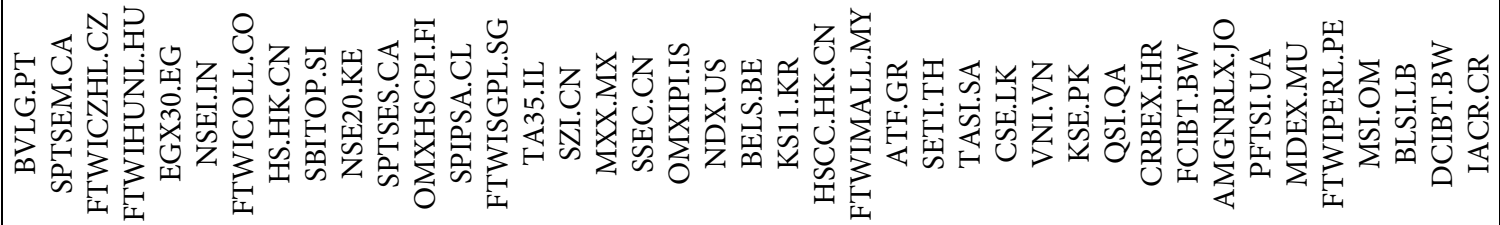

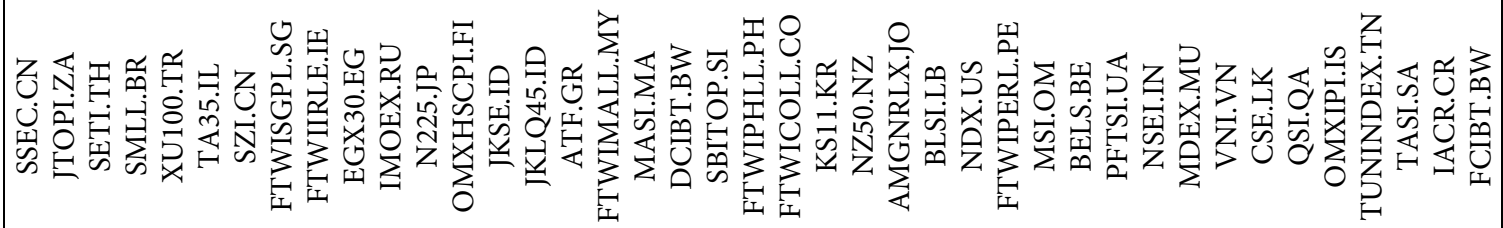

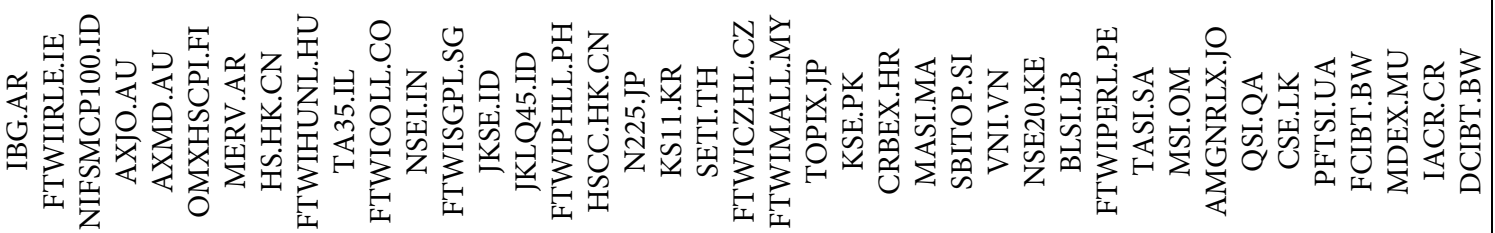

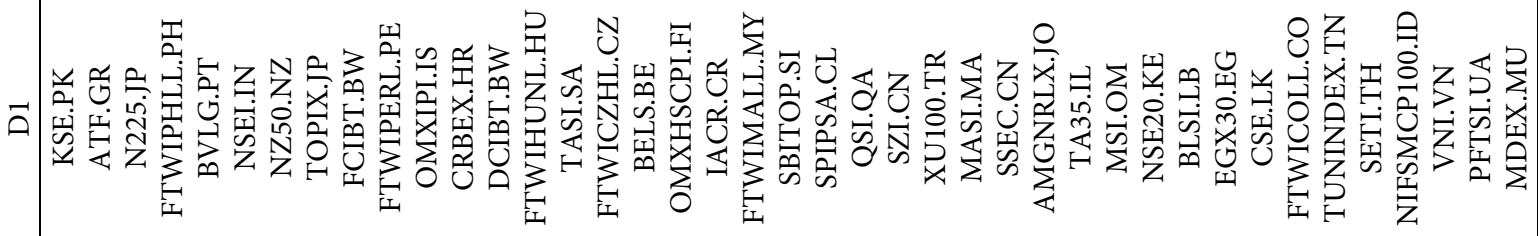




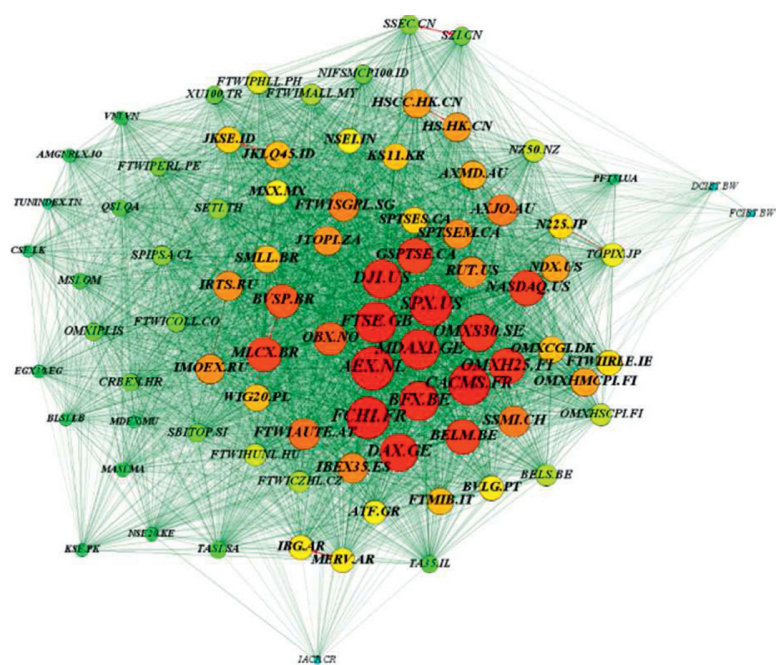

D1

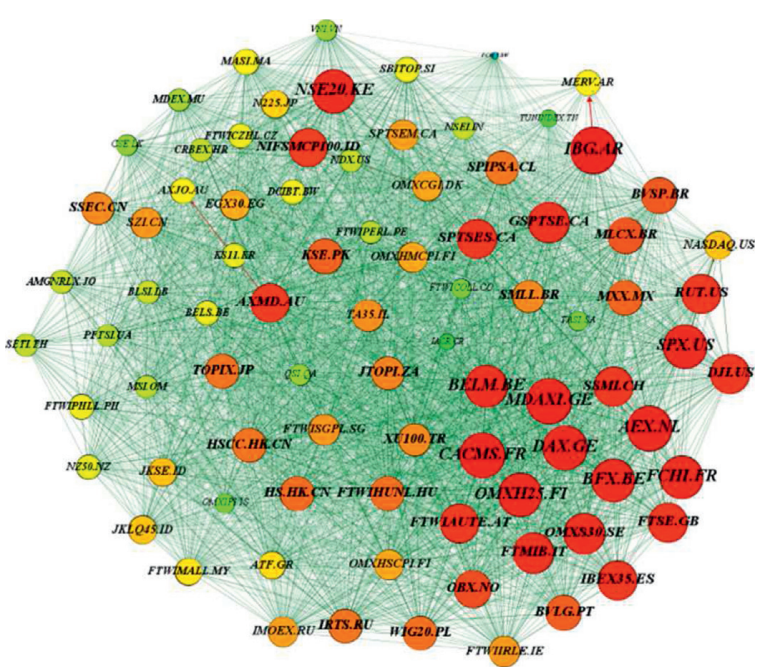

D3

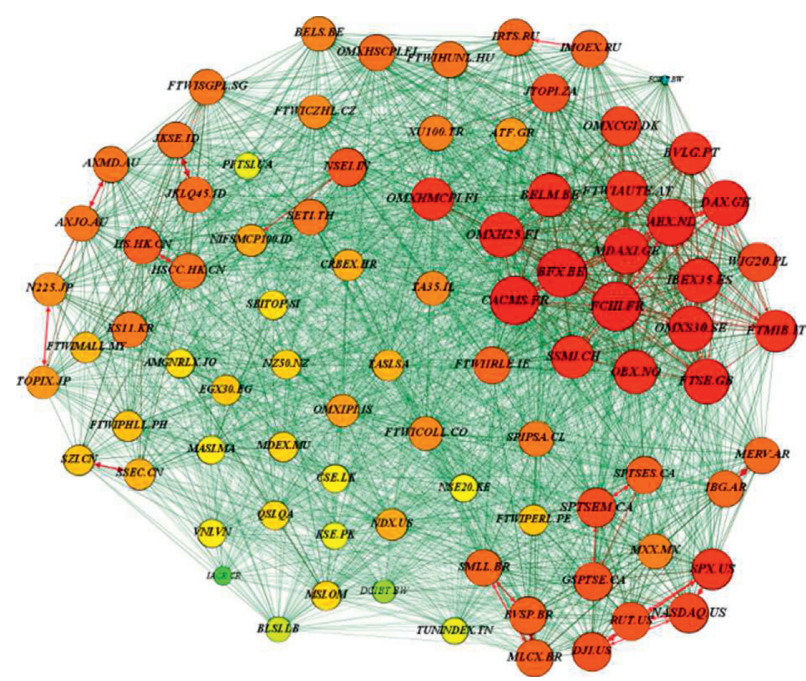

D5

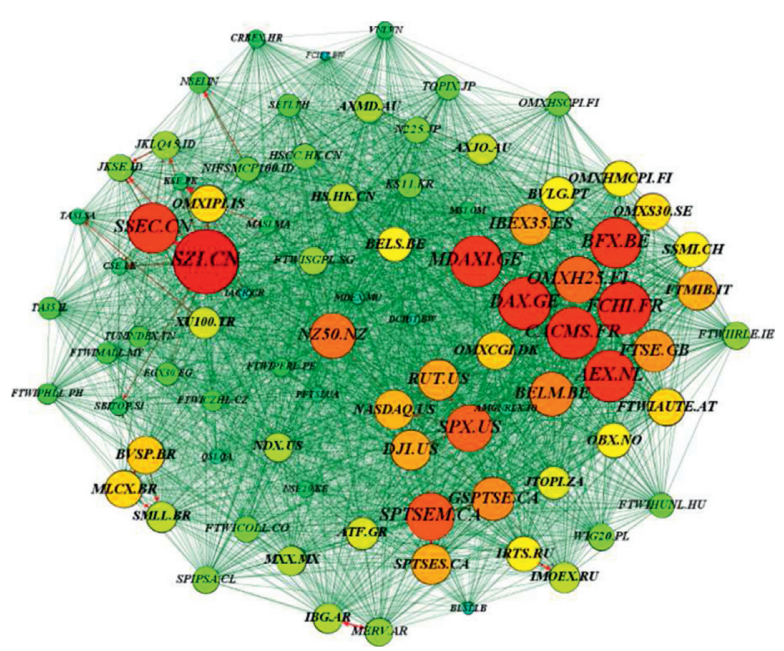

D2

(a)

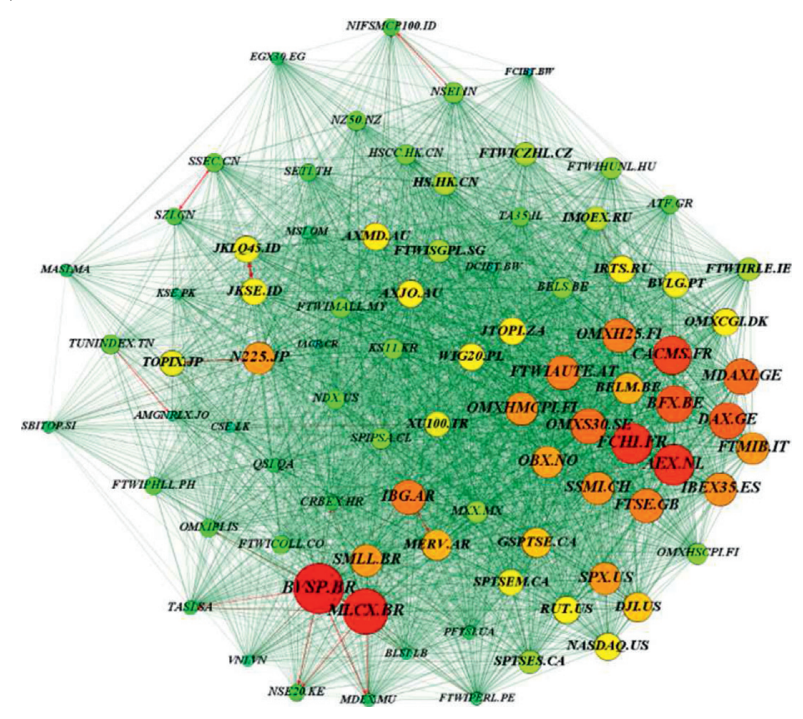

D4

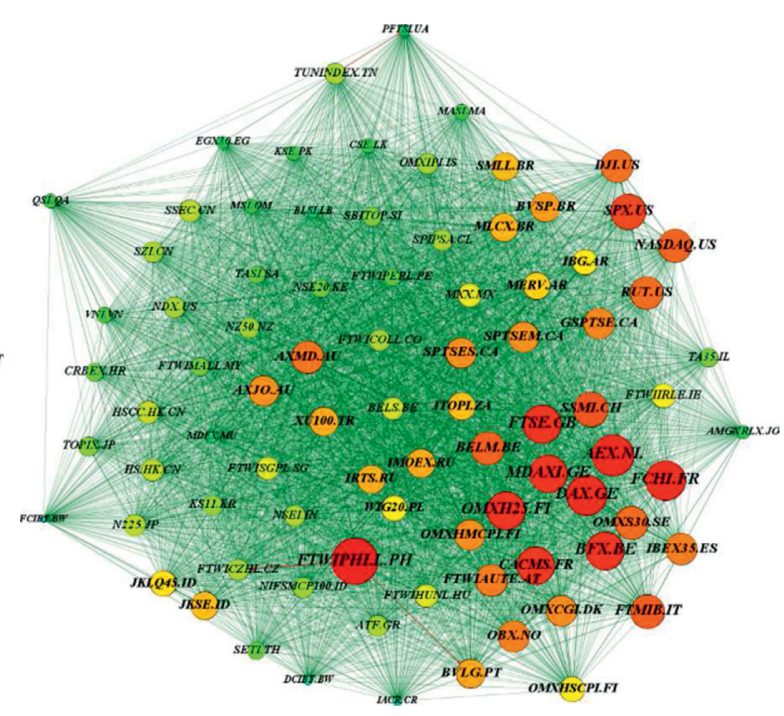

D6

(b)

Figure 4: Continued. 


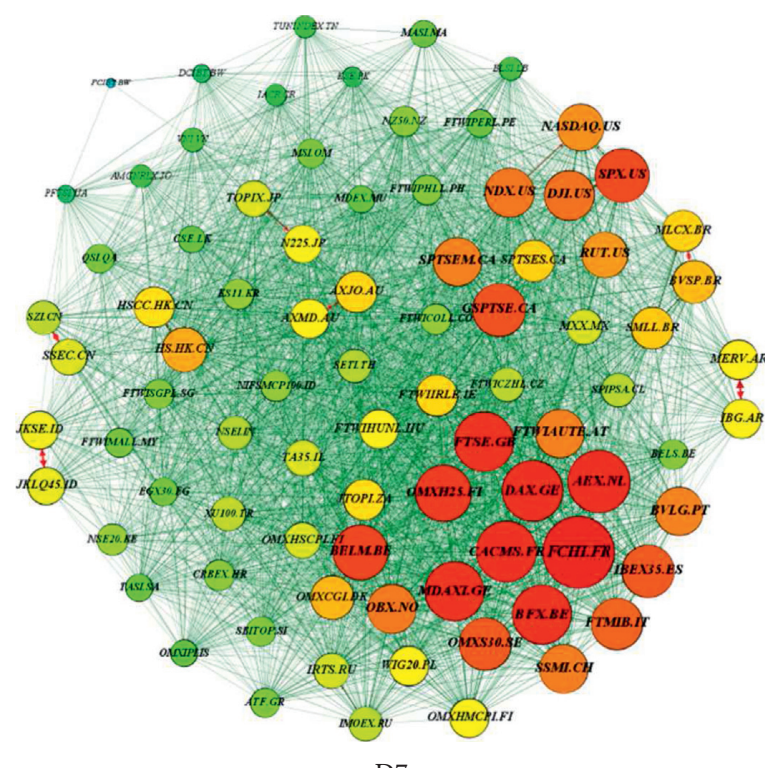

D7

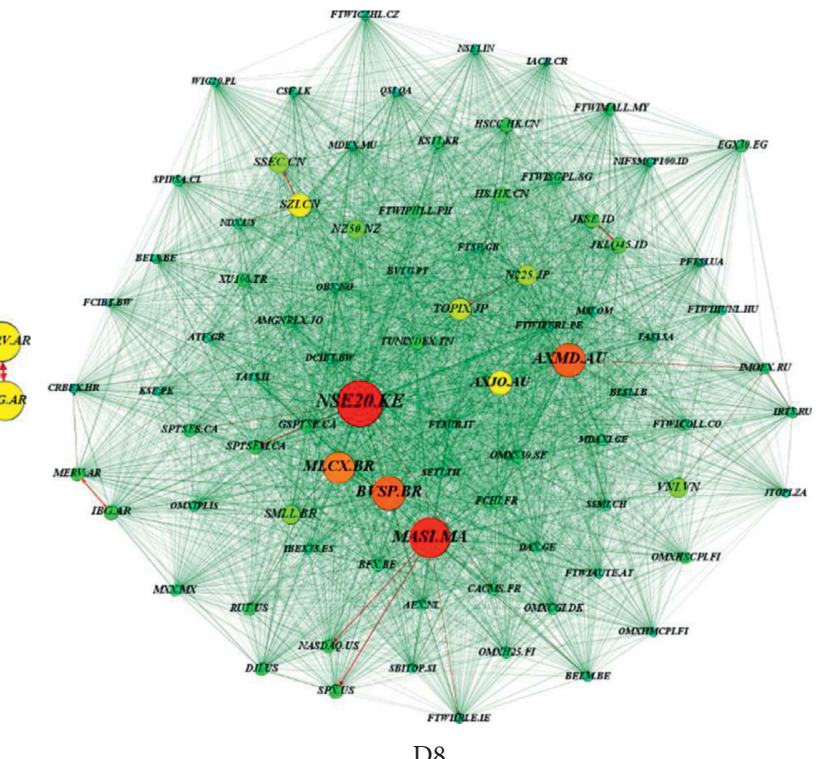

D8

(c)

Figure 4: Multiscale network connectedness. Notes: (1) the size of nodes and nodes' names and colors all indicate total risk spillover to others, with the risk spillover effect from high to low as red (C90407 DB2104), yellow (FAF616), green (81F505), and blue (47E1F5). (2) The obvious directional red line marks the high value of the pairwise connectedness among the indexes, that is, the high-correlated stock markets, which appears mostly between markets within country, and cross-country but within continents. (a) Low frequency (D1 D2). (b) Moderate frequency (D3 D6). (c) High frequency (D7 D8).
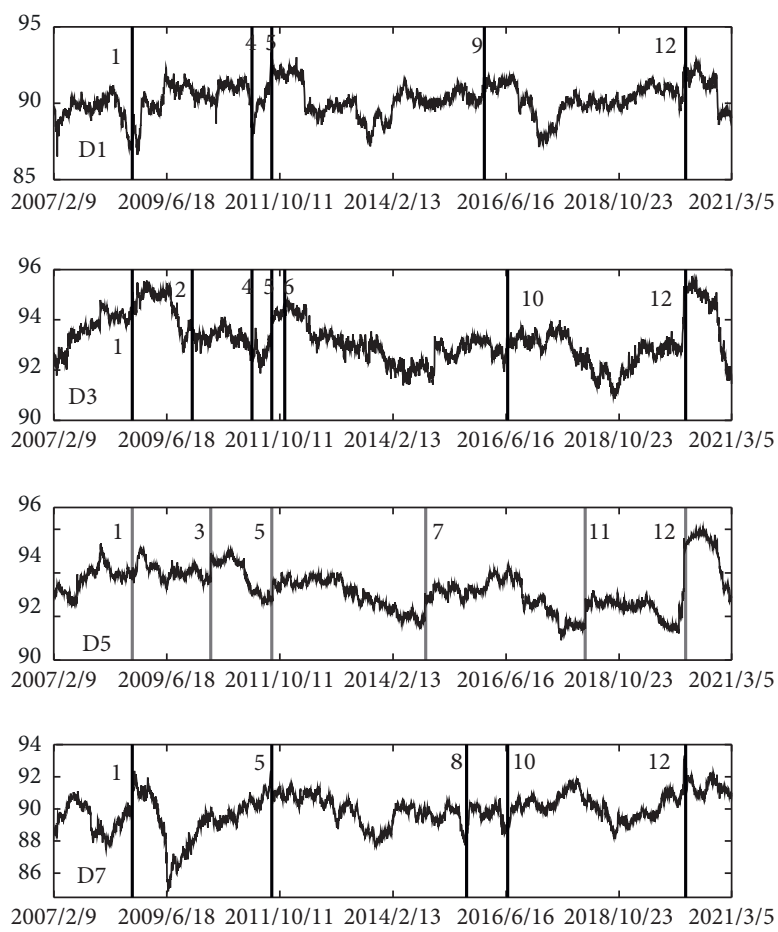
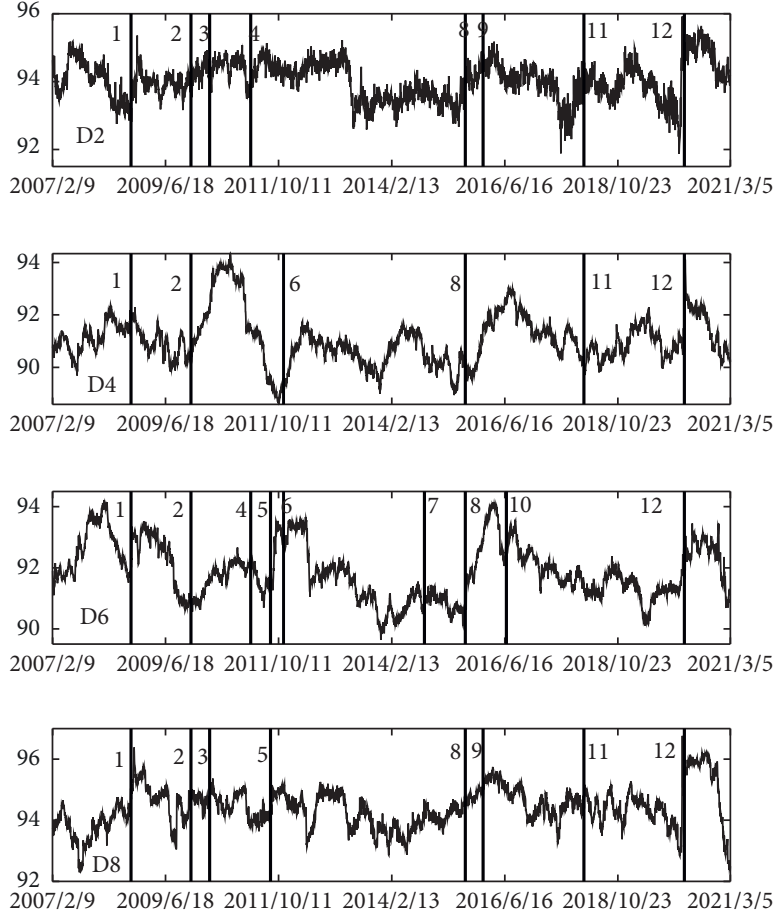

Figure 5: Total risk spillover effect at multiple frequencies. Notes: (1) rolling estimation, 160-day window, connectedness measure at horizon of 12 days. (2) The marked numbers are events, consistent with Figure 3.

At most frequencies, there are obvious cross-country clusters, with Asian and African countries on the left and European and American countries on the right. At a low frequency (scales D1 D2), the aggregation of the risk contagion in European and American countries at D2 is broken when another country located in other regions (China) contributes more of the total risk. With the average to value increasing at scale D2, the average node size also increases. 

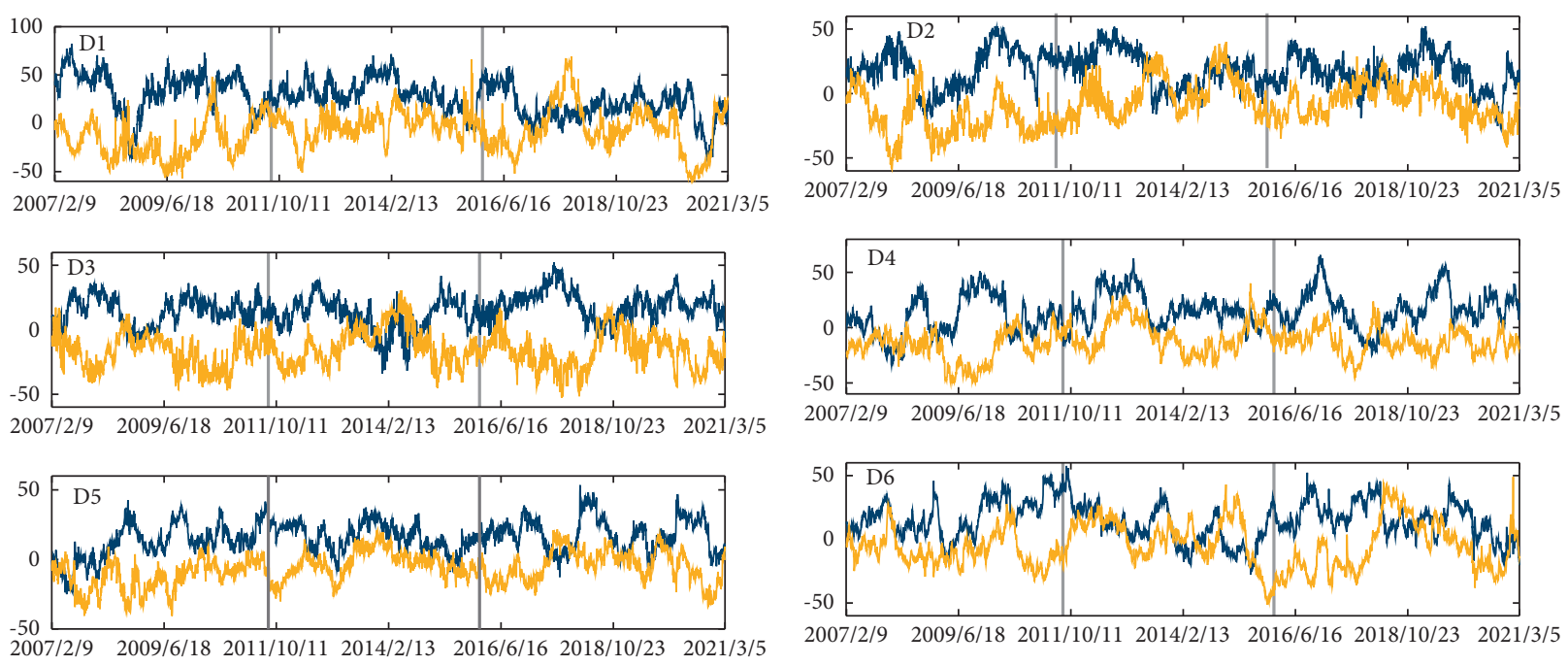

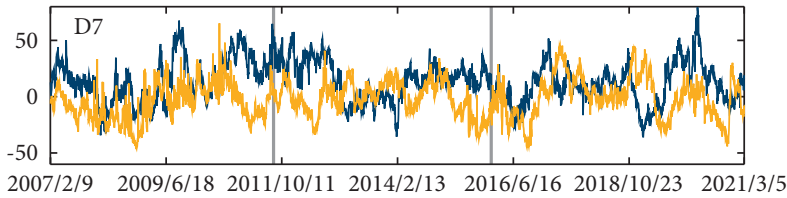

(a)

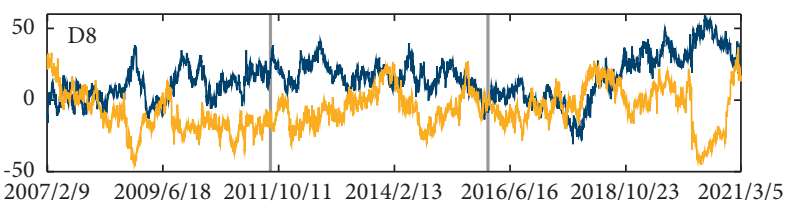

(b)

Figure 6: Dynamic multiscale NET risk spillover effect of the US and mainland China stock market. Notes: the shaded area marks the two events: (a) the United States lost its AAA long-term sovereign credit rating and lowered it by one notch to AA+ (August 5, 2011); (b) the first trading day after the "circuit breaker" mechanism was introduced (January 4, 2016).

At a moderate frequency (scales D3 D6), the large numbers of red and orange distributions at D3 and D5 indicate that risk contagion is evenly distributed in different regions. Although the US and European countries are the main net risks to others, these countries are scattered in different regions as opposed to the D1 scale, and the American countries gather in a region relatively isolated from Europe. In addition, at scale D4, when Brazil becomes a risk center, it moves relatively far from the other American countries; and the red lines connected to Brazil stretch out to Mauritius, Kenya, Vietnam, Saudi Arabia, and Portugal located in South Asia, East Africa, and Western Europe. At scale D6, the Philippines acts as the risk center but is still remote from smaller risk center such as the US, Australia, and some major European countries.

At a high frequency, the degree of dispersion of most countries is high, and the entire figures become round shapes. However, at scale D8, the risk spillover effect of the markets is much less than that of scale D7, which means that the risk contagion concentrates on a few countries (Kenya, Brazil, Morocco, and Australia) with the highest frequencies.

4.2.2. Dynamic Analysis. The analysis of pairwise connectedness is essential in the rolling sample, which helps us identify the variation in risk contagion across sovereign countries over time and makes macroprudential policies applicable. In Figure 5, we plot the total tail risk connectedness over 160-day rolling sample windows. We find some revealing patterns in Figure 5 that the total connectedness has gone through several cycles at all frequencies but is sensitive to different events. It is noticeable that the 2020 COVID-19 outbreak increased the risk contagion among stock markets at all frequencies to the highest range. The unprecedented public emergency stirred up panic throughout the world and exacerbated the risk contagion effect across global stock markets $[28,50]$.

At a low frequency (scales D1 D2), stock markets reacted negatively to the Lehman Brothers bankruptcy on September 15, 2008, and caused a small peak at the beginning of the second cycle. However, due to globalization, cross-country stock markets are more connected such that an imminent shock in one country could lead to risk resonance across the globe. Note that, at scale D1, the risk spillover effect rose to a maximum of $93.33 \%$ because of the downgrade of the US sovereign credit rating on August 5, 2011. However, the dramatic change does not apply to scale $\mathrm{D} 2$, where the spillover effect emerges in the high-risk area most of the time. At a moderate frequency (scales D3 D6), risk spillover effect analysis through the recognition of crucial events becomes difficult because of the diverse reactions to different events. At a high frequency (scales D7 D8), the risk spillover effects at these two scales are distinct from each other, with the average effect for all 12 events being $89.81 \%$ at scale D7 and $94.43 \%$ at scale D8.

Despite the difficulty of analyzing the risk spillover effect of all these events at each frequency, we can analyze one certain event under the framework of the net risk spillover effect of the risk-headstream market. We choose a relatively high-risk transmitter (the US) and receiver (mainland China). 
Figure 6 presents the dynamic net risk spillover effect of the US and mainland China stock markets at multiple frequencies. We will analyze this in the context of the downgrade of the US sovereign credit rating in 2011 and the "circuit breaker" mechanism introduced in 2016 in China.

At all frequencies, mainland China reacted dramatically to the peaks of the risk spillover effect of the US. That is, after transmutation occurred in the SPX.US, there was a coincidental lag of the same performance of the SZI.CN as the SPX.US.

In Figure 6, as for the event that occurred in the US, at a low frequency (scales D1 D2), the risk spillover effect of the US market was high on the day the news was released. Despite a short spell of recovery, the SZI.CN increased slightly but did not change the trend of risk moving downward. However, at scale D2, we could not identify this event. At a moderate frequency (scales D3 D6), there is only a sudden increase at scales D3 and D6, and the two indexes tend to react on the same day. At a high frequency (scales D7 D8), the sharp upswings of the two indexes occurred at almost the same time. At the most exquisite scale D8, the impact of the credit downgrade was not evident until approximately a month later (the risk spillover effect of SZI.CN was not intensified until the beginning of September). In conclusion, the risk contagion of the US may be carried over regardless of whether it is in the short or long run, and ergo the US remains a net risk transmitter under one shock from within the country.

As for the event in China, at a low frequency (scales D1 D2), mainland China spread its risk to other markets and became a net risk transmitter but was still unable to "preponderate" the US and returned to its role as a net risk receiver at $\mathrm{D} 1$. Nevertheless, mainland China did not change to be a net risk transmitter, even in the background of this event at D2. At a moderate frequency (scales D3 D6), it appears to be consistent at each scale that mainland China remained a net receiver despite the severity of the event. Contrary to the moderate frequency, mainland China switched from net receiver to transmitter during the event, and the risk contagion exceeded that of the US market at a high frequency. Therefore, mainland China may change to be a net risk transmitter in the short run under shocks from itself, but in the long run, it will not change its role as a net risk receiver. Additionally, in the medium run, there is no evidence that China could be a source of heavy risk.

This gives us the opportunity to develop the insight into the reason why the center at various frequencies has changed, which is that different time scales react distinctly to different events. Specifically, as time passes by, the risk contagion effect of some short-term impact events may decrease; however, some long-term impact events remain influential.

\section{Conclusions}

In this paper, we examine the risk spillover effect of global stock markets including 85 indexes and 62 sovereign countries at multiple frequencies from June 2006 to March 2021. Our research allows for analysis of both the full sample and the rolling sample period of the network under multiple frequencies, which is empirically and statistically authentic, with different episodes of shocks identified. Regarding the methodology, we use the network connectedness estimation introduced by Diebold and Yilmaz [3] to overcome the welldocumented weakness of alternative approaches, and we use wavelet packet decomposition to reconstruct the daily trading returns and LASSO to conduct high-dimensional network estimation. Additionally, we visualize the network connectedness through static and dynamic analysis. Empirically, we discover that the risk spillover effects at the lowest frequency center on developed countries (European countries such as Netherlands, France, UK, and Germany and the North American country of the US). Moreover, at the second lowest frequency, one of the emerging markets, mainland China, could become a risk center. At a moderate frequency, the regionalization of risk contagion becomes evident, with American countries deviating from the European risk cluster and generating their own risk contagion circle. At a high frequency, due to the uncertainty of stock price fluctuations and investor sentiment in a very short period of time, any fast-developing emerging market or developed markets can be a risk center, so it is better not to draw an absolute conclusion. Therefore, when involving the shocks during the whole sample period, the risks concentrate on the developed markets and some of the fast-developing emerging markets like China, Indonesia, Philippines, Kenya, and Morocco. Dynamically, as a supplementation for static full sample results, we conclude that different time scales react differently to various event shocks, which provides cues for the distinct risk centers at different frequencies that occur in static analysis. Specifically, stock markets reacted negatively to events like the Lehman Brothers bankruptcy on September 15, 2008, and the downgrade of the US sovereign credit rating on August 5, 2011, at a low frequency. Moreover, total risk spillover effect becomes quite variable at the moderate frequency. Besides, the effects are distinct from each other at the two high frequencies, with the average effect for all 12 events being relatively small at the second highest frequency, and big at the highest frequency. Lastly, we analyze the net risk spillover effect of a relatively highrisk transmitter (the US) and receiver (mainland China). We find that, more generally, there was a lag of the same performance of the mainland China market as the US market. And the US remains a net risk transmitter under one shock from within the country; however, mainland China may change to be a net risk transmitter in the short run under shocks from itself but will not change its role as a net risk receiver in the long run.

Furthermore, our results introduce the exact global perspective of risk contagion research at the frequency domain, which is of great value for formulating a target warning strategy prior to episodic shocks and stemming the deterioration of stock markets. First, for regulators and policy makers, we recommend the network connectedness of the global stock markets as part of the early-warning systems to monitor the transmission in the channel of the risk contagion among the risk-launching countries and other countries to make macroprudential regulations more opportune and applicable. Second, for portfolio risk managers, they can hedge against shocks according to the nature of 
stock markets in different countries during different time horizons to offset market risks and lock in arbitrage opportunities. Third, for international investors or speculators, they can assess the risk from different countries more effectively and create optimal trading strategies under different time scales, considering their degree of risk tolerance. Overall, our findings contribute to the academic research on the multifrequency network, as well as the more comprehensive coverage of the global stock markets, and offer practical implications of incorporating time frequency in investment decisions for financial practitioners and investors.

Finally, from the perspective of the selection of the data frequency, we use the daily trading data. Nevertheless, investors tend to preacknowledge crucial events in stock markets sensitively and respond in advance. The signals of risk precautions may exist in the behaviors of investors on each trading day. Hence, we will leave the risk contagion effect of events with different natures and include intraday data for future research, which allows for a timely network connectedness analysis and gives real-time recommendations. Moreover, as the value of the variance is constantly positive, the variance decomposition result cannot calculate whether one market contributes positively or negatively to the change of another market, which can be a limitation of our study. Therefore, we will solve this issue in the coming articles.

\section{Data Availability}

The data that support the findings of this study are available in [Investing] at (https://www.investing.com/). These data were derived from the following resources available in the public domain: (https://www.investing.com/indices/worldindices).

\section{Conflicts of Interest}

The authors declare that they have no conflicts of interest regarding the publication of this study.

\section{Acknowledgments}

This work was supported by the National Natural Science Foundation of China (Grant no. 71903097), the Humanity and Social Science Youth Foundation of Ministry of Education of China (Grant no. 18YJC790226), the Social Science Foundation of Jiangsu Province (Grant no. 20EYC011), the Natural Science Foundation of Jiangsu Province (Grant no. BK20190767), China Postdoctoral Science Foundation Funded Project (Grant nos. 2021T140335 and 2021M691635), and the Key Program of Jiangsu Maritime Institute (Grant no. 2017SZZD-01).

\section{References}

[1] M. Billio, M. Getmansky, W. L. Andrew, and L. Pelizzon, "Econometric measures of connectedness and systemic risk in the finance and insurance sectors," Journal of Financial Economics, vol. 104, no. 3, pp. 535-559, 2012.
[2] R. Engle and B. Kelly, "Dynamic equicorrelation," Journal of Business \& Economic Statistics, vol. 30, no. 2, pp. 212-228, 2012.

[3] F. X. Diebold and K. Yilmaz, "On the network topology of variance decompositions: measuring the connectedness of financial firms," Journal of Econometrics, vol. 182, no. 1, pp. 119-134, 2014.

[4] S. H. Kang and S. M. Yoon, "Dynamic connectedness network in economic policy uncertainties," Applied Economics Letters, vol. 26, no. 1, pp. 1-5, 2018.

[5] M. K. P. So, A. Tiwari, A. M. Y. Chu, J. T. Y. Tsang, and J. N. L. Chan, "Visualising COVID-19 pandemic risk through network connectedness," International Journal of Infectious Diseases, vol. 96, pp. 558-561, 2020.

[6] Z. J. Ding and X. Zhang, "The Impact of Geopolitical Risk on Systemic Risk Spillover in Commodity Market: An EMDBased Network Topology Approach," Complexity, vol. 2021, Article ID 2226944, 2021.

[7] N. Antonakakis, I. Chatziantoniou, and G. Filis, "Dynamic comovements of stock market returns, implied volatility and policy uncertainty," Economics Letters, vol. 120, no. 1, pp. 87-92, 2013.

[8] L. Yin and L. Han, "Spillovers of macroeconomic uncertainty among major economies," Applied Economics Letters, vol. 21, no. 13, pp. 938-944, 2014.

[9] J. H. Ko and C. M. Lee, "International economic policy uncertainty and stock prices: wavelet approach," Economics Letters, vol. 134, pp. 118-122, 2015.

[10] X. Y. Wu, T. Y. Liu, and H. B. Xie, "Economic Policy Uncertainty and Chinese Stock Market Volatility: A CARRMIDAS Approach," Complexity, vol. 2021, Article ID 4527314, 10 pages, 2021.

[11] T. Adrian and M. K. Brunnermeier, "CoVaR," American Economic Review, vol. 106, no. 7, pp. 1705-1741, 2016.

[12] S. Avdjiev, P. Giudici, and A. Spelta, "Measuring contagion risk in international banking," Journal of Financial Stability, vol. 42, 2019.

[13] C. Gong, P. Tang, and Y. T. Wang, "Measuring the network connectedness of global stock markets," Physica A: Statistical Mechanics and Its Applications, vol. 535, 2019.

[14] R. Legenzova, A. Gaigalienè, and O. Jurakovaite, "Evaluation of the post-crisis EU banking network connectedness in the global context," Oeconomia Copernicana, vol. 10, pp. 37-53, 2019.

[15] S. H. Kang and J. W. Lee, "The network connectedness of volatility spillovers across global futures markets," Physica A: Statistical Mechanics and Its Applications, vol. 526, 2019.

[16] Y. H. Guo, P. Li, and A. Li, "Tail risk contagion between international financial markets during COVID-19 pandemic," International Review of Financial Analysis, vol. 73, Article ID 101649, 2020.

[17] Z. X. Zhang, Y. Chen, and W. J. Hou, “Asymmetric risk spillover networks and risk contagion driver in Chinese financial markets: the perspective of economic policy uncertainty," Complexity, vol. 2021, Article ID 3169534, 2021.

[18] F. Wu, D. Y. Zhang, and Q. Ji, "Systemic risk and financial contagion across top global energy companies," Energy Economics, vol. 97, Article ID 105221, 2021.

[19] Z. H. Yang, Y. T. Chen, and R. K. Xie, "Research on systematic financial risk measurement and cross-sectoral risk spillover effects of financial institutions in our country," Journal of Financial Research, vol. 10, pp. 19-37, 2018.

[20] G. J. Wang, H. B. Si, Y. Y. Chen, C. Xie, and J. Chevallier, "Time domain and frequency domain Granger causality 
networks: application to China's financial institutions," $F i$ nance Research Letters, vol. 39, Article ID 101662, 2020.

[21] H. B. D. B. Pereira, S. D. R. Raphael, E. J. D. A. Pereira, M. Leão, M. Davidson, P. Ferreira, and J. G. V. Miranda, Network dynamic and stability on European Union," Physica A: Statistical Mechanics and Its Applications, vol. 587, 2022.

[22] Y. H. Ren, W. R. Zhao, W. H. You, and K. K. Zhai, "Multiscale and partial correlation networks analysis of risk connectedness in global equity markets," Physica A: Statistical Mechanics and Its Applications, vol. 573, Article ID 125911, 2021.

[23] E. J. D. A. L. Pereira, P. J. S. Ferreira, F. D. S. Marcus, J. G. V. Miranda, and H. B. B. Pereira, "Multiscale network for 20 stock markets using DCCA," Physica A: Statistical Mechanics and Its Applications, vol. 529, 2018.

[24] W. Mensi, A. R. Al Rababa'a, X. V. Vo, and S. H. Kang, "Asymmetric spillover and network connectedness between crude oil, gold, and Chinese sector stock markets," Energy Economics, vol. 98, Article ID 105262, 2021.

[25] J. H. Liao, X. H. Zhu, and J. Y. Chen, "Dynamic spillovers across oil, gold and stock markets in the presence of major public health emergencies," International Review of Financial Analysis, vol. 77, 2021.

[26] M. Demirer, F. X. Diebold, L. Liu, and K. Yilmaz, "Estimating global bank network connectedness," Journal of Applied Econometrics, vol. 33, no. 1, 2017.

[27] X. Zhang and Z. J. Ding, "Multiscale Systemic Risk and Its Spillover Effects in the Cryptocurrency Market," Complexity, vol. 2021, Article ID 5581843, 2021.

[28] Z. H. Yang, Y. T. Chen, and P. M. Zhang, "Macroeconomic shock, financial risk transmission and governance response under major public emergencies," Management World, vol. 36, no. 5, pp. 13-35+7, 2020.

[29] W. Q. Li, "COVID-19 and asymmetric volatility spillovers across global stock markets," The North American Journal of Economics and Finance, vol. 58, 2021.

[30] B. Abuzayed, E. Bouri, N. Al-Fayoumi, and N. Jalkh, "Systemic risk spillover across global and country stock markets during the COVID-19 pandemic," Economic Analysis and Policy, vol. 71, pp. 180-197, 2021.

[31] J. A. Batten and C. Kearney, "Interdependence and integration in emerging European financial markets," Emerging European Financial Markets: Independence and Integration Post-Enlargement, vol. 6, pp. 1-14, 2006.

[32] S. Kim and F. In, "The relationship between stock returns and inflation: new evidence from wavelet analysis," Journal of Empirical Finance, vol. 12, no. 3, pp. 435-444, 2005.

[33] N. G. Emmanuel, A. A. S. Frederick, and M. A. Anokye, "Drivers of stock prices in Ghana: an empirical mode decomposition approach," Mathematical Problems in Engineering, vol. 2021, Article ID 2321042, 2021.

[34] Z. Q. Gong, M. W. Zou, X. Q. Gao, and W. J. Dong, "Research on the heterogeneity of empirical mode decomposition and wavelet decomposition based on nonlinear time series analysis," Acta Physica Sinica, vol. 8, pp. 3947-3957, 2005.

[35] J. Liang, "High-frequency perspective information disclosure of stock market reaction," Journal of Financial Research, vol. 12, pp. 165-178, 2007.

[36] S. C. Huang, "Wavelet-based multi-resolution GARCH model for financial spillover effects," Mathematics and Computers in Simulation, vol. 81, no. 11, pp. 2529-2539, 2011.

[37] R. Gençay and D. Signori, "Multi-scale tests for serial correlation," Journal of Econometrics, vol. 184, no. 1, pp. 62-80, 2015.
[38] H. A. Marfatia, "A fresh look at integration of risks in the international stock markets: a wavelet approach," Review of Financial Economics, vol. 34, 2017.

[39] T. Berger and R. Gençay, "Improving daily Value-at-Risk forecasts: the relevance of short-run volatility for regulatory quality assessment," Journal of Economic Dynamics and Control, vol. 92, 2018.

[40] L. Yang, L. Yang, and S. Hamori, "Determinants of Dependence Structures of Sovereign Credit Default Swap Spreads between G7 and BRICS Countries," International Review of Financial Analysis, vol. 59, pp. 19-34, 2018.

[41] Z. B. Zhou, L. Lin, and S. X. Li, "International stock market contagion: A CEEMDAN wavelet analysis," Economic Modelling, vol. 72, 2018.

[42] A. Michis and T. Sapatinas, "Wavelet instruments for efficiency gains in generalized method of moment models," Studies in Nonlinear Dynamics \& Econometrics, vol. 11, no. 4, 2011.

[43] C. Siebenbrunner, M. Sigmund, and S. Kerbl, "Can bankspecific variables predict contagion effects?" Quantitative Finance, vol. 17, no. 12, pp. 1-28, 2017.

[44] Z. S. Ouyang, Y. Huang, Y. Jia, and C. Q. Luo, "Measuring systemic risk contagion effect of the banking industry in China: a directed network approach," Emerging Markets Finance and Trade, vol. 56, no. 6, pp. 1-24, 2020.

[45] S. Mallat, A Wavelet Tour of Signal Processing, Academic Press, New York, NY, USA, 3rd edition, 2009.

[46] F. X. Diebold and K. Yilmaz, "Better to give than to receive: predictive directional measurement of volatility spillovers," International Journal of Forecasting, vol. 28, no. 1, pp. 57-66, 2012.

[47] R. Tibshirani, "Regression shrinkage and selection via the lasso," Journal of the Royal Statistical Society: Series B, vol. 58, no. 1, pp. 267-288, 1996.

[48] M. K. Brunnermeier and M. Oehmke, "Chapter M18 Bubbles, financial crises, and systemic risk," Handbook of the Economics of Finance, vol. 2, pp. 1221-1288, Elsevier, Amsterdam, Netherlands, 2013.

[49] W. Y. Ye, K. L. Jiang, and X. Q. Liu, "Financial Contagion and the TIR-MIDAS Model," Finance Research Letters, vol. 39, Article ID 101589, 2020.

[50] M. Davidovic, "From Pandemic to Financial Contagion: High-Frequency Risk Metrics and Bayesian Volatility Analysis," Finance Research Letters, Article ID 101913, 2021. 